\title{
Precautionary, Preventive Measures and Alternatives in Pediatric Dental Practice during and Post-COVID-19
}

\author{
Nandlal Bhojraj ${ }^{1}$, Raghavendra Shanbhog ${ }^{2}$, Anoop N Kochouseph ${ }^{3}$, Ragavee Veeramani ${ }^{4}$, Amira Imtiaz $^{5}$
}

\begin{abstract}
Aim: To review on the current preventive and nonaerosol-generating practices available for a pediatric dentist.

Background: Life of a dentist revolves around air turbine drills and ultrasonic devices. COVID-19 spreads through respiratory droplets and through contact routes. Dental instruments generate high amounts of aerosols with contaminated saliva and blood, which would be hazardous to the dentist and the other healthcare workers and which can have serious implications on cross-infection and disease transmission. Air turbine drills help in improved efficiency and reduced chairside time. Until it is safe to go back to full-fledged air turbine tooth preparation, there are some alternative options that can be used to treat patients, which could avoid the use of such aerosol generation.

Review results: The treatment modalities include instruments and devices that do not make use of air turbine drills and hence can be called nonaerosol-generating procedures. Some of the procedures include hand scaling, atraumatic restoration treatment, silver diamine fluoride application, extraction, and others.

Conclusion: The abovementioned procedures are minimally invasive and can be considered as a best suitable option in this current situation when treatment is required.

Clinical significance: This review suggests the treatment modalities to be done considering the COVID-19 pandemic that involves crosscontamination in pediatric dentistry.

Keywords: COVID-19 pandemic, Dental cavity preparation, Dental practice pattern, Pediatric dentistry.

World Journal of Dentistry (2020): 10.5005/jp-journals-10015-1751
\end{abstract}

\section{INTRODUCTION}

A novel viral pneumonia outbreak that started from the city of Wuhan, China, and spread globally was termed coronavirus disease (COVID-19) by the World Health Organization (WHO) on February $11,2020 .{ }^{1}$ The symptoms range from fever, cough, fatigue, sputum production, headache, hemoptysis, and diarrhea. ${ }^{2}$

Serious complications, such as acute respiratory distress syndrome, arrhythmia, and shock may also be seen especially in patients over 60 years and with underlying comorbidities (e.g., diabetes, hypertension, and cardiovascular disease). ${ }^{1}$

COVID-19 is transmitted through droplet inhalation (coughing, sneezing), contact transmission (contact with nasal, oral, and eye mucous membrane), and through aerosols formed during certain medical procedures. ${ }^{3}$ Salivary glands have been shown to act as virus reservoirs; saliva of even asymptomatic people is being shown to help in disease propagation. ${ }^{2,4}$ One of the major concerns in dental clinics and hospitals is the droplet and aerosol transmission of COVID-19. Most dental procedures generate a large number of aerosols, which when mixed with blood and saliva could make it a potential major source of transmission.

While the abovementioned transmission pathways are common in the treatment procedure of any dental patient, pediatric patients present additional risks of transmission. The use of removable appliances or auxiliary elements in orthodontics entails risks of contamination if handling is not carried out with due precautions. ${ }^{4}$ Another problem is related to a child's difficulty in using personal protective equipment (PPE) during medical visits. Finally, the presence of caregivers, whom the pediatric dentist cannot avoid to interact with, increases the risk drastically.

Here we discuss the general precautionary measures that a dental professional and a dental assistant should follow while
${ }^{1-5}$ Department of Pediatric and Preventive Dentistry, JSS Dental College and Hospital, JSS Academy of Higher Research, Mysore, Karnataka, India

Corresponding Author: Nandlal Bhojraj, Department of Pediatric and Preventive Dentistry, JSS Dental College and Hospital, JSS Academy of Higher Research, Mysore, Karnataka, India, Phone: +91 98805 67890, e-mail: dr_nandlal@yahoo.com

How to cite this article: Bhojraj N, Shanbhog R, Kochouseph AN, et al. Precautionary, Preventive Measures and Alternatives in Pediatric Dental Practice during and Post-COVID-19. World J Dent 2020;11(4): 338-344.

Source of support: Nil

Conflict of interest: None

treating patients and propose some alternative elective treatment modalities for pediatric dental professionals, during and after this pandemic.

\section{Precautions}

- Pre-appointment screening and patient protection: Patient treatment need should be evaluated using teledentistry or other remote modalities prior to the appointment confirmation. Always fix the appointment and discourage walk-in patients to help minimize transmission risk. Teledentistry can also be used as a novel tool to help the dentist make introductions to the child, thereby reducing their fears and improving in-office time. ${ }^{5}$ Masks and alcohol-based hand rub must be mandatory and any patient without a mask should be provided the same. 
- Temperature check: Any patient in the acute febrile phase is not recommended to visit a dental clinic. The body temperature of the patient should be measured with an infrared contact-free forehead thermometer and a mandatory self-declaration form should be signed by the patient or by the parents (for pediatric patients) before they are taken to the dental operatory. The declaration form should include the health status of the patient and also emphasize the risk of transmission via dental-based aerosol production.

- Hand hygiene: Hand hygiene should be sustained before and after patient examination, before and after dental procedures, before and after coming in contact with the surroundings and equipment, and before and after contacting the mucosa, damaged wound, blood, or any body fluid and secretion. ${ }^{6}$

- Precautionary measures for patients attenders: Patient attenders should be avoided, except in the case of pediatric patients, where it can be minimized to a single parent. Since, they will be in the operatory and they are also considered to be the primary contact of the patient, proper PPE should be provided to the attenders as well, based on the type of the procedure. If allowed inside the operatory, the attenders should be advised not to touch any of the operatory surfaces with bare hands. Alternatively, a transparent barrier can be stimulated in the operatory between the workplace and the mother/ caregivers area, where the parent/caregiver can be present to watch over the procedure as well as help the child to reduce their anxiety.

- Personal protective measures: Along with working clothes (autoclavable scrubs), an extra disposable protective layer should be worn on the outside. The use of three-layered face protection is always advised, which includes an N95 respirator, a surgical mask, and then a face shield. Besides this, disposable head cap, disposable latex/nitrile gloves, shoe covers, protective goggles, and face shield are also to be used.

- Preoperational antimicrobial mouth rinse: The use of chlorhexidine is not effective against COVID-19 according to the National Health Commission of the People's Republic of China. Instead, the use of oxidative agents such as $1 \%$ hydrogen peroxide or $0.2 \%$ povidone as a preprocedural mouth rinse is recommended. COVID-19 is vulnerable to oxidation and this step may help in reducing viral salivary load.

- Aerosol-generating procedures: Ultrasonic and sonic scalers, air polishing, air-water syringe, high-speed handpieces, air abrasion, and slow-speed handpieces are all known to produce aerosols. ${ }^{7}$ In such cases, the use of high-evacuation suction and dental dams helps to minimize droplet spatter and aerosols. ${ }^{8}$ The use of rubber dams, especially in cases where high-speed handpieces and dental ultrasonic devices are used, helps in reducing the generation of contaminated airborne particles. It has been reported that the use of rubber dam could significantly reduce airborne particles within a 3-feet diameter of the operational field by $70 \% .{ }^{9}$ Use of anti-retraction dental handpiece is strongly recommended as an extra preventive measure for cross-infection. ${ }^{10}$ Another major concern is the ventilation of the room in which the procedure is done.

- Sterilization and disinfection: Effective and efficient infectioncontrol procedures should be exercised by all dentists and in-office personals. The dental handpiece can be sterilized externally with the help of autoclaving and internally it can be achieved by chemiclave. This should be done in order to kill the spores inside the high-speed handpieces, which may survive autoclaving. ${ }^{10}$ Infection control of the waterlines is also vital. There are two ways to disinfect water lines; it can be continuous chemical treatment during a dental procedure or intermittent chemical treatment, which are done between the procedures. An easy and safe option is the use of $0.02 \%$ hydrogen peroxide continuously or $0.25 \%$ hydrogen peroxide once a week in the dental-unit reservoir. ${ }^{11}$ A guide on sterilizing and disinfecting dental instruments and materials appears in Table 1.

- Radiographic examination: Extraoral radiographs should be taken, whenever possible, as intraoral techniques may induce coughing. While taking an intraoral radiograph, the film or sensor should be covered with an additional disposable plastic sleeve. This additional outer layer should be removed by the patient and the inner one by the clinician, and both should be properly disposed.

- Medical waste disposal: All medical waste, especially personal protective materials, should be marked while discarding, transported timely to the temporary storage area, and disposed of according to the required waste management protocol.

- Maxillofacial injury: In case of severe oral and maxillofacial trauma, the patient should undergo hospital-based care. Since the RT-PCR test requires specific labs and is time-consuming, a chest CT should be prescribed to exclude suspected infection.

\section{Preventive Guidelines}

In the current scenario, when minimal dental checkups and elective procedures are being performed, there is a high potential of an increased dental disease burden. To keep this in check, certain preventive guidelines can easily be followed at home.

Parents should be advised to:

- Avoid placing a child to bed with a bottle.

- Avoid dipping pacifiers in sugar-containing foods, like honey, sugar, etc.

- Avoid providing the child with a nonspill cup or sippy cup for drinking.

- Reduce use of beverages other that breast milk, infant formula, and water until 1 year of age.

- Begin weaning from bottle and to follow age-appropriate nutrition guidelines. ${ }^{12}$

Patients should be categorized and treated according to their risk level based on the caries risk assessment. Preventive care with 1,000 ppm fluoridated toothpastes, application of fluoride varnishes (at specified intervals), and additional remineralizing agents for arresting/reversing white spot lesions should be carried out. ${ }^{13-17}$

\section{Alternatives \\ Oral Prophylaxis}

While manual scaling with a handheld scraping instrument was standard in the past, modern dentists and hygienists are increasingly using ultrasonic scaling devices. These new tools use ultrasonic vibrations to remove replaque and tartar from the teeth while producing high amounts of aerosol. This is unfavorable in the present situation as aerosol generation could be hazardous for the patient, operator, and the assistant. Breininger et al. showed manual hand scaling to be remarkably effective in plaque removal and bacterial debridement. ${ }^{18}$ Thus, as responsible dentists, we need to revert to the traditional treatment of hand scaling with intermittent rinsing using $1 \% \mathrm{H}_{2} \mathrm{O}_{2}$ and $0.2 \%$ povidone-iodine to prevent contamination from a patient. 
Table 1: Guide on sterilizing and disinfecting dental instruments and materials

\begin{tabular}{|c|c|c|c|}
\hline & Steam autoclave & Dry heat oven & $\begin{array}{l}\text { Chemical disinfection/ } \\
\text { sterilization }\end{array}$ \\
\hline Burs & + (except carbon steel) & + & + \\
\hline Dappen dishes & + & + & + \\
\hline Endodontic instruments (broaches, files, reamers) & + & + & + \\
\hline Glass slabs & + & + & + \\
\hline Hand instruments—stainless steel & + & + & + \\
\hline Handpieces autoclavable & + & + & + \\
\hline Contra angles, nonautoclavable handpieces & - & - & + \\
\hline Impression trays-metal & + & + & + \\
\hline Impression trays plastic & - & - & + \\
\hline Instrument tray setups & + & + & + \\
\hline Mirrors & & + & + \\
\hline Orthodontic pliers & $\begin{array}{l}+ \text { (high-quality stainless } \\
\text { steel) }\end{array}$ & + & + \\
\hline Polishing wheels and disks & - & - & + \\
\hline Removable prostheses & - & - & + \\
\hline Rubber dam-carbon steel clamps & - & + & + \\
\hline Metal frames & + & + & + \\
\hline Plastic frames & - & - & + \\
\hline Punches & - & + & + \\
\hline Prophylaxis cups & + & - & + \\
\hline Saliva evacuators, ejectors-low-melting plastic (discard preferred) & - & - & + \\
\hline Saliva evacuators-high-melting plastic & + & + & + \\
\hline Stones diamond, polishing & + & + & + \\
\hline Stones-sharpening & + & + & - \\
\hline Surgical instruments stainless steel & + & + & + \\
\hline Ultrasonic scaling tips & + & - & + \\
\hline X-ray equipment_-plastic film holders, collimating devices & - & - & + \\
\hline
\end{tabular}

\section{Treatment for Caries with No Signs of Pulpal Inflammation}

Minimally invasive dentistry (MID) concept, i.e., conservation of tooth structure and selective caries removal, without the use of aerosol generation should be followed. The use of the atraumatic restorative technique (ART) and the application of silver diamine fluoride (SDF) are discussed below.

Atraumatic restorative technique: The ART was introduced in Tanzania in 1987 and is defined as "a minimally invasive care approach in preventing dental caries and stopping its further progression.. ${ }^{19}$ The ART involves two components: sealing the deep pits and fissures with pit and fissure sealants and removal of soft denatured dentin to create an access for the restoration. The removal of dentin is done using sharp spoon excavators and the cavity is then sealed with a glass ionomer cement (GIC). GIC is the choice of restoration because of its chemical bonding to the teeth and fluoride release. ${ }^{20}$

In a systematic review and meta-analysis done by Raggio et al., ${ }^{21}$ the authors concluded that ART restorations have a similar success rates to conventional restorative techniques in occlusal and proximal restorations in primary teeth, especially in primary molars.

In the year of the COVID-19 crisis and high disease transmissibility, where aerosol generation is nothing short of dangerous, ART is a great treatment option in both primary and permanent teeth in order to arrest and delay further caries progression.
Silver diamine fluoride: Silver diamine fluoride, composed of ammoniacal silver nitrate, was first introduced in the 1960s in Japan. The American Association of Pediatric Dentistry (AAPD) formulated guidelines for its use in $2017^{22}$ and it is now available worldwide under several brand names.

About 38\% SDF (containing 44,800 ppm of fluoride) works by utilizing the antibacterial activity of silver and the remineralizing potential of fluoride. Metallic silver reacts with bacterial enzymes and nucleic acid, causing protein denaturation and cell lysis. Fluoride ions combine with calcium ions and form calcium fluoride, a precursor of fluorapatite, leading to remineralization Thus, an active dentinal cavity is arrested. ${ }^{22}$ The method of application is followed according to AAPD 2017. ${ }^{23}$

The disadvantage of SDF is that it causes discoloration of dentin. This can be masked by application of a layer of glass ionomer cement over it-a technique called as the SDF-modified atraumatic restorative technique (SMART). Silver diamine fluoride application is contraindicated in caries involving pulp or in teeth showing signs of pulpal inflammation. Concerns about toxicity of silver and fluoride are present, but at this concentration in clinical use, SDF is proven to be safe. ${ }^{22}$

Chibinski ${ }^{24}$ reported that caries arrest by SDF was $66 \%$ greater when compared to traditional materials in his systematic review and meta-analysis and concluded that SDF causes both arrest and prevention of further caries in primary teeth. 
In the present situation of COVID-19, SDF is a safe, minimally invasive, evidence-based, and inexpensive alternative for caries arrest, as it does not involve caries excavation through hazardous aerosol generation.

\section{Treatment for Caries with Signs of Pulpal Inflammation}

In case of deep caries, the caries removal can be done with a sharp excavator or a slow-speed handpiece without water irrigation. The heat generated while using the handpiece can be reduced by giving intermittent breaks during the procedure and with the use of a minimal quantity of water in a syringe. Always use a high-vacuum suction along with the procedure and the patient should be prohibited from rinsing and spitting. It is advised that the clinicians work in a 11 o'clock or 12 o'clock position to avoid coming in direct face-to-face contact with the patient. Magnification will help to maintain a safer distance from the patient while working but appropriate sterilization and disinfection of the magnifying equipment should be done. Also, the air pressure on the three-way syringe should be kept to a minimum, in order prevent any aerosol generation while air drying the tooth/working area.

Leaving a layer of remaining affected dentine followed by a capping agent (indirect pulp capping) helps in the formation of tertiary dentine, which helps to avoid complex pulp treatment.

Complete excavation of caries leading to pulp exposure might require pulpotomy or pulpectomy in primary teeth.

In a tooth that is indicated for pulpectomy, the caries excavation can be done with a sharp spoon excavator or a slow-speed handpiece under rubber dam isolation to minimize aerosol contamination. Single-sitting pulpectomies are advised whenever possible. According to Mathewson, the main indications for pulpectomies are primary incisors with resultant pathologic conditions (in children younger than $4-4.5$ years) and primary second molars, before the eruption of 6 years' molars. ${ }^{25}$ In other cases, especially in posterior teeth with a useable abutment tooth, extraction of primary molars followed by placement of space maintainer should be the general rule.

\section{Crown Preparation}

Avoid placing Zirconia crowns as it requires tooth preparation and aerosol generation. A feasible alternative is using the Hall technique, described below.

Hall technique: Dr Norna Hall, from Scotland, introduced an unconventional way of crown placement using preformed metal crowns, known as the Hall technique. This technique does not involve local anesthesia and any crown preparation or caries excavation and hence, no aerosol generation. ${ }^{26,27}$

The success rate of the Hall technique is based on the sealing ability of the crown. The biofilm is physically prevented from accessing carbohydrate from the oral cavity. This arrests an active lesion into a noncariogenic one.

Multiple studies have examined success rates of the Hall technique vs conventional treatment and no statistically significant difference was seen. ${ }^{28}$ The occlusal stability while applying this technique is long debated. Innes et al., ${ }^{28}$ in their prospective study concluded that a mean increase of $1.1 \mathrm{~mm}$ in vertical dimension was observed immediately after the placement of a hall crown. This was reduced to $0.3 \mathrm{~mm}$ in 2 weeks' time. The authors attributed this change to the compensation from the intrusion of the crowned tooth and intrusion of the opposing tooth as well. The permanent tooth bud was unharmed in this process.

\section{Esthetic Dentistry}

Resin infiltration technology, a microinvasive technique, can be used in tooth discolorations caused by mild to moderate dental fluorosis and molar incisor hypoplasia to give brilliant esthetic results. ${ }^{29}$ It reinforces, fills, and stabilizes demineralized enamel without drilling or sacrificing the healthy tooth structure.

Composite resins are also excellent esthetic restorative materials. For a discolored tooth, noninvasive laminates can be performed. ${ }^{30}$ They can also be used for diastema closure, improving/ modifying tooth size and shape, luting, and core build-up.

The self-etching technique can be followed with a slight modification to help reduce the use of air syringe. Start with tooth preparation using a rubber cup with low-speed micromotor to remove the debris. Etch with the usual procedure and wash off gently using a syringe of distilled water to reduce backsplash. Finally, use chip blower to gently dry the surface and followed by the usual bonding procedure.

The use of indices made from wax-up or celluloid crown forms for anterior teeth is also a good way to reduce chairside time and increase patient satisfaction, without compromising on the overall result.

\section{Management of Oral Surgical Procedures}

All intra-alveolar extraction procedures can be performed with due caution. Avoid aerosol-generating procedures such as bone cutting or trimming. Nonaerosol-generating procedures such as frenectomy and mucocele excision can be performed, but with proper personal protection and sterilization protocols.

\section{Management of Traumatic Dental Injuries (TDIs)}

Oral injuries contribute to about $5 \%$ of all bodily injuries across all ages. ${ }^{31}$ The recent ADA practice guidelines on the COVID-19 outbreak classify TDIs involving facial bones and with uncontrolled bleeding as an emergency. ${ }^{32}$

Prior patient evaluation should be done using teledentistry. If a nonemergent injury (enamel infractions, enamel fracture, concussion injury, subluxation) is diagnosed, the patient/parent is reassured and elective treatment can be deferred. In the case of an emergency (uncontrollable bleeding with gingival and mucosal lacerations, complicated crown fractures, crown-root fractures, root fracture, extrusive, intrusive, and lateral luxations, avulsion, and fracture of alveolar bone), the patient should be treated in-office with proper precautions according to IADT guidelines..$^{33-35}$ Aerosol-generating procedures must be avoided wherever possible. ${ }^{32}$ Procedures requiring suturing and splinting can be done in-office under emergencies. In the case of multiple fractures of facial bone, the patient must be referred to an oral surgeon for further management.

\section{Management of Children Undergoing Orthodontic Treatment}

Since the orthodontic practice involves minimal aerosol generation, an orthodontic practice can be at relatively less risk for transmission of the coronavirus.

While bonding orthodontic brackets and attachments, follow the same pattern for etching and bonding as discussed previously. Interproximal reduction can be done using IPR strips and care should be taken while debonding and changing archwire to avoid splatter and any fly away. 
If a child is using a removable orthodontic appliance, emphasis should be on correct hand hygiene measures before inserting the device into the oral cavity. Removable appliances should be cleaned thoroughly by the patient by soaking it in diluted povidone-iodine before appliance adjustment.

\section{Management of Prosthetic Treatment}

Blood and saliva from dental impressions may carry high concentrations of potentially infective viruses or bacteria that can produce a vicious cycle of cross-contamination. Impressions should be gently rinsed under water to remove blood and saliva and then disinfected. Among the disinfectants, 2\% glutaraldehyde (Cidex, Glutarex, Korselex), 5.25\% sodium hypochlorite (Clorox), and 1\% iodophors (Wescodyne) have been used variably for disinfecting these surfaces. It is recommended that impression materials should not be exposed to disinfectants for more than 30 minutes. If an impression is made from a high-risk patient, the case should be marked on the outside of the container to alert the laboratory. Cases received from the dental laboratory should be washed with soap or detergent, disinfected, and rinsed well before the prosthesis is placed in the patient's mouth. All packing materials should be discarded after use to avoid cross-contamination. ${ }^{36}$ Other than the widely used disinfecting solutions, the ultraviolet chamber has also been shown to effectively reduce the microbial load from impression materials. ${ }^{37}$

\section{Management of Children with Special Healthcare Needs (SHCNs)}

The AAPD defines SCHN as "any physical, developmental, mental, sensory, behavioral, cognitive, or emotional impairment or limiting condition that requires medical management, health care intervention, and/or use of specialized services or programs. The condition may be congenital, developmental, or acquired through disease, trauma, or environmental cause and may impose limitations in performing daily self-maintenance activities or substantial limitations in a major life activity. Health care for individuals with special needs requires specialized knowledge, as well as increased awareness and attention, adaptation, and accommodative measures beyond what are considered routine." ${ }^{\prime 38}$ Dental caries in children with SHCNs is twice as much as those compared to general population. ${ }^{39}$ The incidence of dental trauma is also high in those requiring SHCNs. ${ }^{40}$ This calls for the need of special dental care for these children. During dental treatment, these children often need in-office-based sedation or hospitalbased anesthesia. Sedation techniques can be followed after proper initial medical evaluation and proper disinfection methods. If nitrous oxide-oxygen inhalational technique is followed, then the use of disposal nasal hoods have to be used; the tubings have to be sterilized in an appropriate manner with an EPA-certified chemiclave or autoclave procedure (if the tubes are heat tolerant).

\section{Hospital Care Dentistry}

Pediatric dental care usually involves hospital-based care under general anesthesia. The American Society of Anesthesiologist (ASA) have requested surgeons to defer from elective treatment. The ASA also recommends to minimize the aerosol-generating procedure in the operatory and minimize the number of healthcare professional to be present inside the operatory and during pre-, peri-, and postoperative care. A designated pre-and postoperative room is recommended to be used in case of the COVID-19-positive or a suspected COVID-19-positive patient. The following are the recommendations by ASA:
- Reduction of surgical and interventional procedures: Only emergency and urgent procedures must be carried out. All elective procedures must be postponed. ${ }^{41}$

- Anesthesia work environment: The ASA recommends an escalation of standard of practice during airway management for all patients to reduce exposure to secretions. ${ }^{5}$

- During intubation and other aerosol-generating procedure, the following protocol has to be followed. ${ }^{42,43}$

These include:

- Designating the most experienced anesthesia professional available to perform intubation, if possible.

- Wearing PPE including:

- Either an N95 mask, for which one has been fit-tested, or a powered air-purifying respirator (PAPR)

- A face shield or goggles

- A gown

- Surgical Gloves

- Avoiding awake fiberoptic intubation unless specifically indicated.

- Consider a rapid sequence induction (RSI) in order to avoid manual ventilation of patient's lungs and potential aerosolization. If manual ventilation is required, apply small tidal volumes.

Table 2: Summary of the procedures

\begin{tabular}{|c|c|}
\hline Treatment procedure & Treatment choices \\
\hline Oral prophylaxis & 1. Hand scaling \\
\hline \multirow{3}{*}{$\begin{array}{l}\text { Management of carious le- } \\
\text { sion not involving the pulp }\end{array}$} & 1. ART \\
\hline & 2. SDF application \\
\hline & 3. Hall technique \\
\hline \multirow{2}{*}{$\begin{array}{l}\text { Management of carious } \\
\text { lesions involving the pulp } \\
\text { in primary teeth }\end{array}$} & $\begin{array}{l}\text { 1. Pulpotomy/pulpectomy (if abut- } \\
\text { ment teeth is not present) }\end{array}$ \\
\hline & $\begin{array}{l}\text { 2. Extraction and space maintainer (if } \\
\text { abutment teeth is present) }\end{array}$ \\
\hline \multirow{2}{*}{$\begin{array}{l}\text { Management of lesions } \\
\text { involving the pulp in young } \\
\text { permanent teeth }\end{array}$} & 1. Partial/complete pulpotomy \\
\hline & 2. Root canal therapy \\
\hline \multirow[t]{2}{*}{ Esthetic management } & 1. Resin infiltration \\
\hline & 2. Composite veneer/buildups \\
\hline S. S. Crown & 1. Hall technique \\
\hline Traumatic dental injuries & $\begin{array}{l}\text { 1. Nonaerosol-generating procedures } \\
\text { can be done-like pulp protec- } \\
\text { tion, application of flexible splints. } \\
\text { Removal of splints can be deferred } \\
\text { to a later appointment (refer pulp } \\
\text { exposure for management of com- } \\
\text { plicated fracture and esthetics for } \\
\text { treatment concerning esthetics) }\end{array}$ \\
\hline \multirow[t]{4}{*}{ Orthodontics } & 1. Interproximal_IPR strips \\
\hline & $\begin{array}{l}\text { 2. Bonding-use water in syringe and } \\
\text { gentle air blow using a chipblower }\end{array}$ \\
\hline & $\begin{array}{l}\text { 3. Debonding and changing the } \\
\text { archwire-care to avoid splatters } \\
\text { and fly away }\end{array}$ \\
\hline & $\begin{array}{l}\text { 4. Patient hand hygiene while insert- } \\
\text { ing removable appliances }\end{array}$ \\
\hline \multirow[t]{3}{*}{ Oral surgical procedure } & 1. Extractions-intra-alveolar \\
\hline & $\begin{array}{l}\text { 2. Minor oral surgical procedures with } \\
\text { proper caution }\end{array}$ \\
\hline & $\begin{array}{l}\text { 3. Avoid transalveolar extractions and } \\
\text { trimming of bone }\end{array}$ \\
\hline
\end{tabular}


- Maintenance of anesthesia station: Proper disinfection after every case is recommended with an EPA-certified chemical disinfectat. $^{5}$

The summary of the procedures is given in Table 2 .

\section{Conclusion}

During these tough times, as dental healthcare professionals, we must be well informed of the disease and treat patients with maximum precaution. Depending on the patient compliance, comprehensive treatment care should be provided to reduce multiple appointments. The end of the pandemic will have to mark the beginning of innovative techniques and approaches for clinical management in pediatric dentistry.

\section{References}

1. Meng L, Hua F, Bian Z. Coronavirus disease 2019 (COVID-19): Emerging and future challenges for dental and oral medicine. J Dent Res 2020;99(5):481-487. DOI: 10.1177/0022034520914246.

2. Peng X, Xu X, Li Y, et al. Transmission routes of 2019-nCoV and controls in dental practice. Int J Oral Sci 2020;12(1):9. DOI: 10.1038/s41368-0200075-9.

3. Liu J, Liao X, Qian S, et al. Community transmission of severe acute respiratory syndrome coronavirus 2, Shenzhen, China, 2020. Emerg Infect Dis 2020;26(6):1320-1323. DOI: 10.3201/eid2606.200239.

4. Wang Y, Zhou CC, Shu R, et al. Oral health management of children during the epidemic period of coronavirus disease 2019. Sichuan Da Xue Xue Bao. Yi Xue Ban 2020;51(2):151-154. DOI: $10.12182 / 20200360101$.

5. ADA. What Constitutes a Dental Emergency? 2020.

6. Hand Hygiene Guidance | Hand Hygiene |CDC.

7. Harrel Dds SK, Molinari J. Aerosols and splatter in dentistry. J Am Dent Assoc 2004;135(4):429-437. DOI: 10.14219/jada.archive.2004.0207.

8. Dental Settings $\mid C D C$.

9. Samaranayake LP, Reid J, Evans D. The efficacy of rubber dam isolation in reducing atmospheric bacterial contamination. ASDC J Dent Child 1989;56(6):442-444.

10. Abichandani S. Cross contamination in dentistry: a comprehensive overview. 2012;2(1):3-9.

11. DePaola LG, Grant LE. Infection control in the dental office: a global perspective DePaola LG, Grant LE 1st ed., ed. Springer; 2020. p. 216.

12. Tinanoff N, Palmer CA. Dietary determinants of dental caries and dietary recommendations for preschool children. J Public Health Dent 2000;60(3):197-206. DOI: 10.1111/j.1752-7325.2000.t b03328.x.

13. Ramos-Gomez F, Ng MW. Into the future: keeping healthy teeth caries free: pediatric CAMBRA protocols. J Calif Dent Assoc 2011;39(10): 723-733.

14. Featherstone JDB, Chaffee BW. The evidence for caries management by risk assessment (CAMBRA ${ }^{\oplus}$ ). Adv Dent Res 2018;29(1):9-14. Available from: http://journals.sagepub.com/doi/10.1177/00220345 17736500.

15. Best Practices: Caries-Risk Assessment And Management 220 The Reference Manual Of Pediatric Dentistry Purpose. 2007.

16. American Academy of Pediatric Dentists. Policy on use of fluoride. Oral Heal Policies 2014. 43-44. Available from: http://doi. wiley.com/10.1002/chin.200327230\%5Cnpapers3://publication/ doi/10.1002/chin.200327230.

17. Toumba KJ, Twetman S, Splieth C, et al. Guidelines on the use of fluoride for caries prevention in children: an updated EAPD policy document. European Archives of Paediatric Dentistry, vol. 20. Springer; 2019. pp. 507-516.

18. Breininger DR, O'Leary TJ, Blumenshine RVH. Comparative effectiveness of ultrasonic and hand scaling for the removal of subgingival plaque and calculus. J Periodontol 1987;58(1):9-18. DOI: 10.1902/jop.1987.58.1.9.
19. Frencken JE, Leal SC, Navarro MF. Twenty-five-year atraumatic restorative treatment (ART) approach: a comprehensive overview. Clin Oral Investig 2012;16(5):1337-1346. DOI: 10.1007/s00784-0120783-4.

20. Anusavice KJ. Phillips' Science of Dental Materials: Middle East and African Edition. Elsevier Health Sciences; 2003. pp. 21-195.

21. Raggio $D P$, Hesse $D$, Lenzi $T L$, et al. Is atraumatic restorative treatment an option for restoring occlusoproximal caries lesions in primary teeth? A systematic review and meta-analysis. Int J Paediatr Dent. 2012;23(6):435-443. Available from: http://doi.wiley.com/10.1111/ ipd.12013.

22. Crystal YO, Niederman R. Evidence-based dentistry update on silver diamine fluoride. Dental Clinics of North America, vol. 63. W.B. Saunders; 2019. pp. 45-68.

23. AAPD. Policy on the use of silver diamine fluoride for pediatric dental patients. Pediatr Dent 2017;39(6):51-53. Available from: http://www. ncbi.nlm.nih.gov/pubmed/29179318.

24. Chibinski AC, Wambier LM, Feltrin J, et al. Silver diamine fluoride has efficacy in controlling caries progression in primary teeth: a systematic review and meta-analysis. Caries Res 2017;51(5):527-541. DOI: $10.1159 / 000478668$.

25. Mathewson RJ, Primosch RE. Fundamentals of pediatric dentistry. Quintessence Books 1995. p. 276.

26. Evans DJP, Southwick CAP, Innes NP, The Hall technique: a pilot trial of a novel use of preformed metal crowns for managing carious primary teeth. 2006; Available from: http://www.dundee.ac.uk/tuith/Articles/ rt03.htm.

27. Innes NPT, Stirrups DR, Evans DJP, et al. A novel technique using preformed metal crowns for managing carious primary molars in general practice - a retrospective analysis. Br Dent J 2006;200(8):451454. DOI: 10.1038/sj.bdj.4813466.

28. Innes NPT, Evans DJP, Bonifacio CC, et al. The hall technique 10 years on: questions and answers. Br Dent J 2017;222(6):478-483. DOI: 10.1038/sj.bdj.2017.273.

29. Koirala AS. Minimally invasive cosmetic dentistry - concept and treatment protocol. Cosmet Dent 2009. 28-33.

30. Andreasen JO, Andreasen FM, Frances M, et al. Textbook and color atlas of traumatic injuries to the teeth Andreasen JO, Andreasen FM, Frances M, et al., ed. 5th ed., 2018. p. 1064.

31. Di Giovanni T, Eliades T, Papageorgiou SN. Interventions for dental fluorosis: a systematic review. Journal of Esthetic and Restorative Dentistry, vol. 30. Blackwell Publishing Ltd; 2018. pp. 502-508.

32. Dental B, Starts C, Care DD, ADA Interim Guidance for Minimizing Risk of COVID-19 Transmission Table of Contents After Dental Care is Provided ADA Interim Guidance for Minimizing Risk of COVID-19 Transmission Before Dental Care Starts. pp. 1-8.

33. Diangelis AJ, Andreasen JO, Ebeleseder KA, et al. Guidelines for the management of traumatic dental injuries: 1. Fractures and luxations of permanent teeth. Pediatr Dent 2016;38(6):358-368.

34. Andersson L, Andreasen JO, Day P, et al. Guidelines for the management of traumatic dental injuries: 2 . Avulsion of permanent teeth. Dent Traumatol 2012;28(2):88-96. DOI: 10.1111/j.16009657.2012.01125.xAvailable from: http://www.ncbi.nlm.nih.gov/ pubmed/22409417.

35. Malmgren B, Andreasen JO, Flores MT, et al. Guidelines for the management of traumatic dental injuries: 3 . Injuries in the primary dentition. Pediatr Dent 2016;38(6):377-385.

36. Guidelines for infection control in the dental office and the commercial dental laboratory. council on dental therapeutics. council on prosthetic services and dental laboratory relations. J Am Dent Assoc 1985;110(6):969-972. DOI: 10.14219/jada.archive. 1985.0016.

37. Samra RK, Bhide SV. Efficacy of different disinfectant systems on alginate and addition silicone impression materials of Indian and international origin: a comparative evaluation. J Indian Prosthodont Soc 2010;10(3):182-189. DOI: 10.1007/s13191-010-0040-y.

38. American Academy of Pediatric Dentistry. Definition of special health care needs. Pediatr Dent 2016;38(special issue):16. 
39. Dziwak $M$, Heinrich-Weltzien $R$, Limberger $K$, et al. Dental health and odontogenic infections among 6- to 16-year-old German students with special health care needs (SHCN). Clin Oral Investig 2017;21(6):1997-2006. DOI: 10.1007/s00784-016-1988-8.

40. Silva Silveira ALNME, Magno MB, Soares TRC. The relationship between special needs and dental trauma. A systematic review and meta-analysis. Dent Traumatol 2020;36(3):218-236. Available from: https://onlinelibrary.wiley.com/doi/abs/10.1111/edt. 12527.
41. https://www.asahq.org/about-asa/newsroom/newsreleases/2020/03/asa-apsf-joint-statement-on-non-urgent-careduring-the-covid-19-outbreak.

42. https://www.asahq.org/about-asa/governance-and-committees/ asa-committees/committee-on-occupational-health/coronavirus/ clinical-faqs.

43. World Federation of Anesthesiologist, COVID-19 guidance for anaesthesia and perioperative care providers [Internet]. 2020. Available from: www.wfsahq.org. 